\title{
Exploring Reasons on Lexical Borrowing from English Language (L2) to Sindhi Language (L1)
}

\author{
Iram Panhwar \\ MS Scholar, Mehran University of Engineering \& Technology, Jamshoro \\ Rosy Ilyas \\ Assistant Professor, Mehran University of Engineering \& Technology, Jamshoro \\ Syed Waqar Ali Shah \\ Lecturer, Mehran University of Engineering \& Technology, Jamshoro \\ Nishfa Rajper \& Iqra Baloch \\ MS Scholars, Mehran University of Engineering \& Technology, Jamshoro
}

\begin{abstract}
The term lexical borrowing is often used to express the system through which one language borrows words from another language to renew its linguistic system. The current research papers focuses to explore the reasons of borrowing words from English language (L1) into Sindhi language (L1). The current study employs qualitative research methodology to explore the reasons of borrowing words from English language. Research tool used to collect data was semi structured interviews and convenient sampling was taken as a source. Participants were $(\mathrm{n}=5)$ from a public sector university of Sindh. Data was examined and analyzed through thematic analysis. The major reasons behind lexical borrowing discovered were; code switching and code mixing result in borrowing, importance and exposure of English and lack of vocabulary in Sindhi (L1).
\end{abstract}

Keywords: Lexical borrowing, reasons, Sindhi language, English language.

DOI: $10.7176 /$ JLLL/83-03

Publication date: November $30^{\text {th }} 2021$

\section{Introduction}

Language is dynamic not static. It possess some properties of changeability and flexibility through different sources of development like other living organism. The term lexical borrowing is often used to express the system through which one language borrows words from another language to renew its linguistic system (Durkin 2014, Poplack, 2017). The language which adapt lexical items is known as recipient language and the language which gives its lexical items is known as donor language. It is very usual o borrow words from a language and make it part of its own language (Haugen, 1950). Linguists think that this process of exchanging words is natural which occurs because of social forces.

This is globalized era. Everyone is connected with each other. Different cultures are under influence of one another. Because of cultural contact and cultural motivation, languages of their cultures also come in contact with each other. When two different cultures and languages are in contact then exchange of different linguistic items and social norms is natural (Treffers-Dallers, 2007). No one can stop it. In Pakistan, English language is considered as road to success and language of elites. People especially educated people tend to borrow words from English in their conversation to make their language prestigious because English is enjoying a prestigious social status in Pakistan (Rehman, 2006). Those who speaks English fluently or use few words of English language in their native language communication is considered very intelligent. The factors behind status of English in Pakistan is colonization and spread of English during $19^{\text {th }}$ and $20^{\text {th }}$ century.

\subsection{Research Problem}

In Pakistan, Urdu and English are official languages. In Sindh province, Sindhi is official language too. It is among oldest language of Sindh and sub-continent. It is language of medium of instructions, newspapers, media channels and publications (Panhwar 2019). It contains a vast variety of lexical items but still people use to borrow words from English language during communication in Sindhi language (L1) their mother tongue. The Sindhi language used by current Sindhi speakers of $21^{\text {st }}$ century is quite different from old Sindhi language. Through this research work, researcher wants to explore the reasons of lexical borrowing words in their mother tongue Sindhi language (L1) from English language (L2).

\subsection{Research Question}

To better explore the research problem, present study focus to report following question:

Q1 What are the reasons that hold accountable for Sindhi speakers to borrow lexical items from English 
language (L2) in their mother tongue Sindhi (L1)?

\section{Literature Review}

The consequences of effect on one language from another language is borrowing and changes in a language occurs because of it (Lehman, 2013). When two or more than two different languages are in contact with each other, they left some effect on each other in one or other way. It is another thing that one language is under great influence of second language.

Grosjean (2010) clarified the difference between code switching and lexical borrowing as "the temporary shifting of words from one language to another and permanent shifting of words from one language to another respectively and after that those borrowed lexical items work as basic part of recipient language. Sindhi people use to do code switching from English language in their Sindhi conversation (Panhwar. 2018). She further says that apart from code switching, Sindhi speakers tend to borrow lexical items from English language. It is caused because of lack of lexical items in their native language.

Sowers (2017) carried out a research on effect of lexical borrowing from English on Japanese and concluded that today it has become difficult to speak pure Japanese language without using English language words in it. Effect of English language on other language is very common because English language is globalized language and people's psyche for it is that it is dominant, prestigious and superior language. So people of all nations, communities and classes try their level best by themselves to learn and want their children to learn and use English language in their communication. The same scenario is with Sindhi language speakers as well.

Romaine (1989) researched reasons of lexical borrowing that main reason behind lexical borrowing is elite class people. They do code switching in their conversation to show some prestige and status. Later, this trend is adopted and followed by middle and lower class people. Slowly and gradually this mechanism results in lexical borrowing from a prestigious language in a native language. As prestigious language enjoys a dominant status. So people of other languages also wants to enjoy that status and learn prestigious, dominant and globalized language which is English language in current time.

Myers-Scotton (2002) proposed two types of lexical borrowing; cultural borrowing and core borrowing. Former borrowing is need in language because of lack in vocabulary of equivalent items in a language. Those items which are not presented in a language so speakers feel a necessity of new items so they borrow it from another language to fill the gap. These type of borrowing is mostly related to words of science, technology. Few examples of words borrowed in Sindhi language are pizza, hydrogen, computer, Wi-Fi, laptop, television, radio, bus, mobile and the list goes on. Later type of borrowing is core borrowing. It is also called as unnecessary. In type of borrowing the lexical items are already present in host language but still native speakers borrow words from donor language in host language because they feel easy to pronounce certain words of another language instead of their own. In Sindhi language there is word Qalam but native speakers use to say pen/pencil, time instead of waqt and glass instead of Jaman.

When a speaker/writer speaks/writes he doesn't only want to convey message but also tries to leave a good impression on listener/reader. In order to do this, s/he take support of certain words from a language more prestigious than theirs. In Sindhi language there are words Sayunn, Aaloo Chips/Papadr, and Chahn for Spaghetti, Fries and Tea respectively. But educated Sindhi people use English language words because they want to leave a good impression on others and to show that they belong to an upper class. This is because of effect of McDonalization and KFC (Pirzado, 2009).

According to G.A Allana Sindhi language and Indus valley civilization are natively connected with one another and denied that Sindhi language is not daughter language of any other language (Allana, 2002). Original history of Sindhi language is still under arguments.

\section{Research Methodology}

Following the nature of present research problem and question, the researcher has adopted qualitative research methodology. Qualitative methodology is used in research to better understand a situation about which little is known (Corbin \& Strauss 1990). This method is used to collect in depth knowledge about a particular phenomenon. This method is used to collect data through interviews, structured and un-structured interviews, observations and group interviews or discussions.

\subsection{Sampling \& Participants}

It is very important to select wisely the sampling and participants according to research aim and question. Usually, researcher chooses participants on the basis of their knowledge and experience (Cameron, 2005). Nonrandom and convenience sampling is selected because in convenience sampling participants are easily and willingly available. Convenience sampling is also known as accidental sampling. The participants for present study were students of final year of Applied Linguistics from a public sector university of Sindh $(\mathrm{n}=5)$. All 
participants were of Sindhi ethnicity.

\subsection{Data Collection \& Analysis}

Data was collected through semi structured interviews in Sindhi language because participants were more comfortable to share ideas in their own mother tongue (L1). After collecting data, it was transcribe from Sindhi to English language. The data analysis approach for current research work was thematic analysis. Braun and Clarke's model (2006) was used to analyze and report data. Thematic analysis help researcher to understand and analyze the problem from very close view (Marks \& Yardley 2004). There are six steps in Braun and Clarke's model of thematic analysis. The researcher first familiarize herself with data. Then generated codes, searched for themes. After searching themes and reviewing themes, researcher named themes and finally produce the report.

\section{Findings \& Discussion}

According to all participants they borrow lexical items from English language in their conversation because of three main reasons; code switching and borrowing results in lexical borrowing, importance and exposure of English language and vocabulary gap/lack in mother tongue i.e. Sindhi (L1).

Code switching and mixing from English language results in lexical borrowing in Sindhi language. According to P.3: On regular basis I use English language in my conversation. My mother has also adopted English language words because we use those words in our conversation. The act of code switching from English language is replacing Sindhi language words with English language slowly and gradually. Romaine (1998), stated that borrowing is result of code switching by bilingual elite people who use to put lexical items from a dominant language in their native language to show some status and sign of power and prestige.

The second reason of lexical borrowing was found as importance and exposure of English language. Participants said that we have exposure of English language everywhere. Being ELL (English language learner) we have to use English language and words in conversation otherwise people will think that they are not educated, intelligent or hardworking.

P.3 narrated: Another reason is whoever talks English language is considered as intelligent because English is dominant and globalized language. Importance of English language is also important factor because English language is considered as road to success in Pakistan. Those who speak English proficiently can easily get good jobs and handsome salary packages.

Out of 5 participants 4 shared that they have lack of vocabulary in their mother tongue Sindhi. P.2 narrated: Sometimes I forget Sindhi language vocabulary so I feel ease to use English language word there. This is might be because of lack of vocabulary and few words of Sindhi language are typical and they are difficult to pronounce. Participants confessed that they don't know Sindhi meanings of words like talent, confidence, check etc. even they do know Sindhi meaning of most of the words but still they prefer to use English language words because they feel awkward to use pure Sindhi language words in their conversation. They do unnecessary borrowing from English language more than necessary borrowing. According to Styblo (2007), people tend to borrow words from English language even if they are not familiar/fluent in English language specifically if their native language's linguistic items are difficult to pronounce and English language words are easy to utter out.

\section{Conclusion}

The major reasons of current research were found as use of code switching and mixing becomes so usual in Sindhi conversation that it is borrowed slowly and gradually by native speakers. Another reasons is exposure and scope of English language in Pakistan. In Pakistan, English language is official and second language (McArthur, 2002). It is growing and emerging language in Pakistan. So everyone is trying their level best to be proficient in it. It has become difficult to survive without English language in this modern and technological era. Last but not least reason is having lack of vocabulary in Sindhi language in mother tongue. Sometimes they feel difficulty in pronouncing Sindhi language words and feel easy and comfortable with English language words. This process of lexical borrowing is replacing Sindhi language vocabulary and is replaced by English language. Today's generation is using English language words in their mother tongue conversation normally.

\section{References}

Allana, G. A. Dr. (2002). "Sindhi Boli Jo Bun Bunyad" Second Edition (Sindhi), Karachi, Sindhica Academy

Braun, V., \& Clarke, V. (2006). Using thematic analysis in psychology. Qualitative research in psychology, 3(2), $77-101$

Cameron, J. (2005). Focusing on the focus group. Qualitative research methods in human geography, 2(8), 116132

Corbin, J. M., \& Strauss, A. (1990). Grounded theory research: Procedures, canons, and evaluative criteria. Qualitative sociology, 13(1), 3-21. 
Durkin, P. 2014. Borrowed Words: A History of Loanwords in English. Oxford: Oxford University Press.

Grosjean, F. (2010). Bilingual. Harvard university press.

Haugen, E. (1950). The Analysis of Linguistic Borrowing in Languages 26(2), 210-231, New York: Holt, Rinehard and Winston.

Lehmann, W. 2013. Historical Linguistics: An Introduction. London: Routledge

Marks, D. F., \& Yardley, L. (Eds.). (2004). Research methods for clinical and health psychology. Sage

McArthur, T. (2002). The Oxford guide to world English. Oxford: Oxford University Press.

Myers-Scotton, C. (2002). Contact linguistics: Bilingual encounters and grammatical outcomes. Oxford University Press on Demand.

Panhwar, F. Y. A. N. (2018). Multilingualism in Sindh, Pakistan: the functions of code-switching used by educated, multilingual Sindhi women and the factors driving its use (Doctoral dissertation, University of Sussex).

Panhwar, F., Lone, S. T., \& Muhammad, A. F. (2019). The Looming Extinction of Sindhi Language in the Urban Context and Role of a Sindhi Mother. The Women-Annual Research Journal of Gender Studies, 11(11).

Pirzado, A. (2009). Sindhi Language and Literature, First Edition, Sindhi Language Authority, Hyderabad, Sindh.

Poplack, S. 2017. Borrowing: Loanwords in the Speech Community and in the Grammar. New York: Oxford University Press.

Rahman, T. (2006). Language policy, multilingualism and language vitality in Pakistan. In A. Saxena and L. Borin (Eds.), Trends in Linguistics: Status and Politics: Case Studies and Application in Information Technology. Berlin: Water and Gruyter, 73-106.

Romaine, S. (1989). Bilingualism. (1st edition). Oxford: Wiley-Blackwell.

Sowers, A. M. (2017). Loanwords in Context: Lexical Borrowing from English to Japanese and its Effects on Second-Language Vocabulary Acquisition (Doctoral dissertation, Portland State University).

Styblo, M. (2007). English loanwords in modern Russian language.

Treffers-Dallers, J. (2007). A Handbook of Pragmatics, New York: John Benjamins Publishing Company. 